\title{
O mundo, a Amazônia e a região de fronteira no fio da navalha: o Sul e Sudeste do Pará em tempos da pandemia do coronavírus
}

El mundo, la Amazonía y la región fronteriza al filo de la navaja: el sur y el sudeste de Pará en tiempos de la pandemia de coronavirus

The world, the Amazon and the border region on the razor's edge: the South and Southeast of Pará in times of the coronavirus pandemic

Le monde, l'Amazonie et la région frontière sur le fil du rasoir : Sud et Sud-est du Pará en temps de la pandémie du coronavirus

\section{Eudes Leopoldo}

\section{(2) OpenEdition}

\section{Journals}

Electronic version

URL: http://journals.openedition.org/espacoeconomia/13707

DOI: 10.4000/espacoeconomia.13707

ISSN: 2317-7837

\section{Publisher}

Núcleo de Pesquisa Espaço \& Economia

Electronic reference

Eudes Leopoldo, "O mundo, a Amazônia e a região de fronteira no fio da navalha: o Sul e Sudeste do Pará em tempos da pandemia do coronavírus », Espaço e Economia [Online], 18| 2020, Online since 22 April 2020, connection on 21 May 2020. URL : http://journals.openedition.org/espacoeconomia/13707 ; DOI : https://doi.org/10.4000/espacoeconomia.13707

This text was automatically generated on 21 May 2020.

(C) NUPEE 


\title{
O mundo, a Amazônia e a região de fronteira no fio da navalha: o Sul e Sudeste do Pará em tempos da pandemia do coronavírus
}

\author{
El mundo, la Amazonía y la región fronteriza al filo de la navaja: el sur y el \\ sudeste de Pará en tiempos de la pandemia de coronavirus \\ The world, the Amazon and the border region on the razor's edge: the South and \\ Southeast of Pará in times of the coronavirus pandemic \\ Le monde, l'Amazonie et la région frontière sur le fil du rasoir : Sud et Sud-est du \\ Pará en temps de la pandémie du coronavirus
}

\section{Eudes Leopoldo}

\section{Introdução}

1 No amplo espectro de desdobramentos apontados sobre a disseminação da Covid-19 no mundo, o retorno ao espaço privado e as possíveis mudanças geracionais são as mais frisadas. Alguns apontam até que a crise sanitária, que é seguida por crises em todas as dimensões da vida e do espaço, significaria o fim do século XX e a emergência efetiva do século XXI. No entanto, pouco se fala diretamente sobre o domínio das representações, que acaba ficando em segundo plano diante do redemoinho de fatos trágicos sistemáticos, que trazem a tona cotidianamente os limites do que convencionamos chamar de civilização. A própria representação ilumina até que ponto a tragédia que estamos vivendo significa a emergência de um novo mundo com a emergência de contradições inéditas, no qual a verdade ganha um nível de mistificação jamais visto.

2 A emergência da contemporaneidade como a nova condição humana do século XXI em toda sua profundidade ressignifica o mundo do trabalho, o mundo da produção e o mundo das representações. O trabalho remoto; o controle espacial dos corpos; os 
sistemas de distribuição em domicílio; as novas formas de solidariedade orgânica e organizacional; o encontro e a reunião à distância em tempo real; a eclipse do espaço público; a sublimação do espaço privado; o aprofundamento da comunicação e a circulação de produtos do mercado de entretenimento por meio de plataformas virtuais; o sequestro da verdade e as novas indumentárias, costumes, comportamentos e modos de higiene e limpeza são alguns dos processos acirrados que invocam os novos espaços-tempos negativos. Todos esses processos espelham e reproduzem representações do espaço negativo. $O$ espaço absoluto e o espaço abstrato constituem camadas históricas e geográficas do espaço negativo: o espaço do século XXI, produto da simultaneidade entre metropolização e financeirização.

3 O objetivo é então pensar e problematizar, no novo espaço-tempo da pandemia da Covid-19, processos e representações do mundo contemporâneo e sua reprodução na Amazônia e, em particular, na região de fronteira, o Sul e Sudeste do Pará. Pelo pouco tempo de amadurecimento das ideias, é apresentado mais um ensaio do que necessariamente uma análise, no sentido de contribuir com a interpretação de um mundo em metamorfose.

\section{A representação e o mundo em compasso de espera}

Nessa chuva torrencial de imagens e informações que recebemos dia após dia sobre esse microorganismo que deixou mais de 7,5 bilhões de homens em compasso de espera, em um planeta no qual o movimento tornou-se sua razão de ser, o que mais marcou foram algumas das diversas estátuas monumentais pelo mundo inteiro terem ganhado uma máscara. Como símbolo da prevenção contra uma pandemia, que não sabemos ainda ao certo para onde nos levará, a máscara de proteção passa a estar presente não só nos corpos, mas também nas representações. A lembrança imediata do diálogo entre o médico e a mulher sobre as estátuas com vendas nos olhos dentro de uma igreja, durante a fictícia pandemia da cegueira branca descrita por Saramago (1995), inundou os sentidos com a natureza trágica da crise sem precedentes pela qual atualmente passa o que chamamos de humanidade.

5 Não me acreditarás se eu te disser o que tenho diante de mim, todas as imagens da igreja estão com os olhos vendados, Que estranho, por que será, Como hei-de eu saber, pode ter sido obra de algum desesperado da fé quando compreendeu que teria de cegar como os outros, pode ter sido o próprio sacerdote daqui, talvez tenha pensado justamente que uma vez que os cegos não poderiam ver as imagens, também as imagens deveriam deixar de ver os cegos, As imagens não veem, só agora a cegueira é para todos (SARAMAGO, 1995, p. 302).

6 Essa situação fictícia evidencia a colagem entre a realidade e a representação. Trata-se do movimento de representação espelhando a própria realidade. Hoje, quando em vários lugares as máscaras passaram a ser adotadas pela sociedade como proteção contra a Covid-19, cujo uso tem sido crescentemente imposto como norma em muitas cidades, as esculturas como representações humanas, divinas, heroicas, angelicais e antropomórficas estão recebendo a máscara como símbolo da nova condição social. Só agora a pandemia do coronavírus é para todos! O sofrimento dos corpos estende-se para as representações, identificando o contexto hodierno de ascensão de novas experiências do espaço-tempo e de novas lógicas, expressões diretas do espaço negativo. As pulsões de vida e de morte mobilizam os corpos a partir do 
compartilhamento de bloqueios mentais e sociais por conta da pandemia, sendo a máscara um indicativo, desdobrando o "princípio de autoconservação" (ADORNO, HORKHEIMER, [1944] 1985).

7 Os manequins das lojas também estão exibindo o item de proteção em suas faces plásticas, apontando para a criação de um novo nicho de mercado de consumo. A máscara cirúrgica que era de uso comum entre os povos asiáticos de algumas metrópoles, devido a exposição intensa à poluição e enfermidades respiratórias, passou a ser item de proteção mundialmente utilizado contra uma pandemia global com origem identificada e destino incerto. No entanto, agora elas ganharam cores, texturas e formatos diferentes nas últimas semanas.

8 A globalização da máscara usada pela sociedade e suas representações evidencia a gravidade da situação, devido ao alto grau de contágio e letalidade, e as mudanças abissais que estamos vivendo, não só no plano da produção, mas também na estrutura de sentimento. $O$ mundo oriental e o mundo ocidental unificam-se. $O$ inimigo comum criou uma mercadoria que ingressa cada vez mais nos mercados dos diversos países. $\mathrm{O}$ crescimento exponencial da produção das máscaras em larga escala e a demanda acentuada dos governos, instituições e empresas ampliam sua difusão por todo planeta, possibilitando de algum modo o retorno paulatino da circulação e daquilo que Vidal de La Blache ([1921] 1954, p. 59) celebrou como "a enchente da maré humana", ansiosa pela redescoberta do movimento.

9 O recurso à mistificação da realidade também ganha projeção como uma representação que corrobora com a manipulação de falsos debates e pela criação e manutenção de grupos de seguidores conscientes ou inconscientes. Uma delas que se convencionou no enfrentamento do coronavírus foi a falsa dicotomia entre vida e economia alimentada pela difusão de desinformação. As tropas cibernéticas nas redes sociais com a amplificação de ideias e temas feitas por robôs tornou-se uma chave da fecundação de falsas verdades, que se socializam e pautam os debates e os comportamentos.

10 Aquilo que não corresponde aos fatos concretos acaba sendo assimilado como a verdade, mesmo que às vezes haja um consenso em nível mundial contrário à verdade falseada. A manipulação da realidade passa a ser mais uma vez e de maneira intensa a arma fundamental da política neofascista e autoritária que se instala no coração de inúmeros países atualmente. Nietzsche (1966, p. 222) já reclamava no século XIX, desde seu alter ego Zaratustra, de viver sempre entre os homens "com verdades dissimuladas, com as mãos loucas e enlouquecido o coração, rico em piedosas mentiras". No mundo contemporâneo, a mentira suplanta a própria verdade e figura ela mesma como verdade suprema.

11 O trabalho de Kalil e Santini (2020) revela que mais da metade das publicações no Twitter durante a pandemia do Covid-19 e da manifestação pró-governo e contra os demais poderes da República, no dia 15 de março de 2020, foram disparados por robôs, por meio de contas automatizadas, e ciborgues, através de contas semiautomatizadas. Esse apoio ilusoriamente amplificado permite que a dicotomia entre salvar vidas e o retorno da economia aparentemente funcione como a verdade. O neofascismo converte-se em necropolítica, herdeira de um neoliberalismo dos trópicos, que se apresenta como o negativo da economia política contemporânea dos centros dinâmicos desenvolvidos. A farsa da dicotomia entre vida e economia em um país não desenvolvido como o Brasil não chega a ser hegemônica, em virtude de racionalidades políticas baseadas na ciência e nas diretrizes sanitárias internacionais. Nas 
regionalizações brasileiras, como na Amazônia, e em regionalizações mais específicas, como no Sul e Sudeste do Pará, esse conflito e colagem entre realidade e representação reproduzem diferentes determinações.

\section{O mundo, a Amazônia e a fronteira em tempos de pandemia do coronavírus}

12 Na contramão de pensadores como Bauman (1999, p. 76), que falava da "nova liberdade global de movimento", ou de Virilio (1993, p. 53), para quem "a luz da velocidade ilumina o mundo", a pandemia do coronavírus parou o planeta. Em autores como Santos ([1996] 2000), Lencioni (1999), Carlos (2001) e Haesbaert (2010), o movimento e a velocidade são relativos e não colocam em segundo plano o espaço e as fronteiras, pelo contrário. Concordamos que "hoje a mobilidade tornou-se praticamente em uma regra. O movimento se sobrepõe ao repouso. A circulação é mais criadora que a produção" (SANTOS, [1996] 2000, p. 279). A produção do espaço e das fronteiras ganhou uma nova qualidade com esse processo de ampliação e aceleração do movimento e da circulação. No entanto, em tempos de pandemia do coronavírus, compromete-se o movimento e a circulação, parecendo que houve uma regressão no espaço-tempo. Reencontra-se a célula elementar das aglomerações e das cidades: o sedentarismo.

Na Amazônia, esse movimento chega de modo diferenciado. Antes de tudo é necessário evidenciar que nessa região particular não é exatamente a manifestação da forma da cidade, mas a difusão do urbano como modo de vida que marca seu processo de urbanização (OLIVEIRA, 2016). Apesar de que cada vez mais, especialmente na região de fronteira da Amazônia, como no Sul e Sudeste do Pará, há uma gênese desmedida de novas cidades, dando suporte aos grandes projetos econômicos (BECKER, 1990). No limite, chega-se a falar de "cidades da floresta", que possuem "características de pequenas cidades e associadas frequentemente à circulação fluvial" e "forte ligação com as dinâmicas da natureza, da vida rural não moderna e do ritmo da floresta ainda pouco explorada", e de "cidades na floresta", que são aquelas que tendem a se articular principalmente às demandas externas da região, fazendo da floresta um elemento de pouca integração aos novos valores da vida urbana, sendo mesmo sua negação" (TRINDADE JÚNIOR, 2010, p. 239).

14 Tanto as cidades da floresta quanto as cidades na floresta são marcadas por grandes distâncias, cujos percursos podem ser realizados por meio dos rios ou pelas rodovias, e em alguns casos em ambas as modalidades. Essas longas travessias podem significar a diferença entre a vida e a morte, especialmente em casos de surtos virais de rápida difusão. São nas metrópoles regionais, como Manaus e Belém, que encontramos uma maior infraestrutura hospitalar, capaz de atender com mais robustez aos casos mais graves da Covid-19. Mesmo assim, Manaus já apresenta uma demanda mais significativa de pacientes com Covid-19 do que sua oferta de leitos de unidades de terapia intensiva (UTIs), devido a sua forte articulação com os centros dinâmicos do mundo e do território nacional, que facilitou a disseminação da doença. Belém não fica muito distante desse quadro, aproximando-se também de um colapso de seu sistema de saúde. A complexidade e diversidade do processo de urbanização e metropolização na Amazônia (TRINDADE JÚNIOR, 2010; OLIVEIRA, 2016; SANTOS, SOUSA e LIMA, 2019; LIMA, 2019; LEOPOLDO, 2020) e seus diferentes padrões de circulação (OLIVEIRA NETO e 
NOGUEIRA, 2019) demonstram as dificuldades com que a região confronta-se em tempos de coronavírus.

No Pará, há a presença de hospitais de média e alta complexidade especialmente na Região Metropolitana de Belém e nos principais centros urbanos regionais. As políticas nos governos de Lula e Dilma de instalação de unidades de pronto atendimento (UPAs) permitiram a ampliação do acesso ao direito à saúde, possibilitando a chegada desses serviços em algumas cidades pequenas da fronteira amazônica. Outro serviço de saúde importante são as UTIs móveis, produtos de políticas estaduais mais recentes, que corroboraram para que casos mais urgentes tivessem a possibilidade de ser atendidos, assegurando de algum modo a estabilização de pacientes até chegarem em hospitais regionais. Diante do crescimento dos casos da Covid-19, o governo do Estado está instalando 4 hospitais de campanha: em Belém (Região Metropolitana), Marabá (Região do Sul e Sudeste do Pará), Santarém (Região do Baixo Amazonas) e Breves (Região de Marajó), que totalizam 720 leitos.

Fazendo vista grossa à falsa dicotomia entre vida e economia, o Governo do Estado do Pará e governos municipais decretaram o isolamento social como medida necessária para a mitigação da disseminação da Covid-19, evitando um colapso imediato no sistema de saúde. Hoje, o Pará vive um estado de calamidade pública aprovado pelo poder legislativo estadual e com a coordenação de diversas políticas que visam maximizar e otimizar o sistema de saúde pelo poder executivo. Do ponto de vista da disseminação da Covid-19, apresenta-se uma curva de crescimento expressivo, chegando-se em um mês a mais de 900 casos, entre os dias 18 de março, quando do primeiro paciente positivo para a doença, e 20 de abril de 2020, totalizando 35 óbitos para o mesmo período. Do ponto de vista regional, a Região Metropolitana concentra 721 casos confirmados, seguido da Região Nordeste com 72 e da Região do Sul e Sudeste com 30, na data de 20 de abril de 2020.

o Sul e Sudeste do Pará é uma complexa região de fronteira, um canto do mundo que vive em metamorfose permanente. Nela, a disseminação da Covid-19 parece ser um catalisador das mudanças. Com a chegada dos primeiros casos, cidades como Marabá, Xinguara e Redenção estão desertas. Algumas das poucas pessoas em circulação utilizam máscaras de proteção, indicando novos costumes e comportamentos. Essas cidades misturadas e desenraizadas vivem em compasso de espera e, simultaneamente, a maldição e a esperança da fronteira. Mergulha-se nessa transitoriedade das cidades na fronteira e, ao mesmo tempo, na redescoberta da potência da civilização, que se reinventa em tempos da emergência de uma pandemia global.

\section{Considerações Finais}

18 No mundo, na Amazônia e, em particular, no Sul e Sudeste do Pará, estamos ressignificando o nível do privado, que Lefebvre ([1974] 1991) caracterizou pelo habitar e seus lugares. Passamos a aprender a lidar com a realização do habitar, do lazer e do trabalho no espaço privado, proporcionado pelas novas experiências espaço-tempo mediatizadas por tecnologias. Diante do espaço-tempo crítico do coronavírus, ressignificam-se também os níveis $\mathrm{G}$ e $\mathrm{M}$, o primeiro fazendo referência ao global, aos espaços públicos do encontro e da reunião, já o segundo relacionando-se aos lugares de passagem (LEFEBVRE, [1974] 1991). Os espaços públicos e os lugares de passagem foram implodidos, mesmo que temporiamente e de maneira fragmentada, mobilizando novas 
formas e gestos de ser e estar no mundo. Em linhas gerais, os caminhos e os lugares públicos foram redimensionados e a casa ganhou relevo no movimento de produção do espaço.

É bom lembrar os clássicos que mostravam atribuições centrais do geógrafo na análise de dois objetos chaves da reprodução das relações sociais de produção: a estrada e a casa. Brunhes (1962, p. 96) falava que "a forma e o aspecto da estrada são expressões de Geografia Humana que indicam tão bem quanto a forma e o aspecto da casa". Portanto, temos uma contribuição fundamental na interpretação dos novos processos e representações em construção no mundo contemporâneo e seu tempo: o século XXI.

o fundamental é assinalar que o que resta da modernidade e de suas utopias pereceu nas mesmas ruínas em que terminaram os sonhos de uma geração, produto do século XX. Próximos do que defendeu Brum (2020), estamos convencidos de que precisamos urgentemente construir uma nova arquitetônica revolucionária a partir de uma teoria prática do presente e de todas as vozes, especialmente daquelas que foram silenciadas por tanto tempo.

\section{BIBLIOGRAPHY}

BAUMAN, Zygmunt. Globalização: as consequências humanas. Rio de Janeiro: Zahar, 1999.

BECKER, Bertha. Amazônia. São Paulo: Editora Ática, 1990.

BRUM, Eliane. O futuro pós-coronavírus já está em disputa. El País, 08 de abril de 2020.

BRUNHES, Jean. Geografia Humana. Rio de Janeiro: Editora Fundo de Cultura, 1962.

CARLOS, Ana Fani Alessandri. Espaço-Tempo na Metrópole: a fragmentação da vida cotidiana. São Paulo: Contexto, 2001.

HAESBAERT, Rogério. Regional-Global: dilemas da região e da regionalização na geografia contemporânea. Rio de Janeiro: Bertrand, 2010.

KALIL, I. \& SANTINI, R. M. “Coronavírus, Pandemia, Infodemia e Política”. Relatório de pesquisa. Divulgado em 01 de abril de 2020. 21p. São Paulo / Rio de Janeiro: FESPSP / UFRJ. Disponível: https://www.fespsp.org.br/store/file_source/FESPSP/Documentos/Coronavirus-einfodemia.pdf.

LEFEBVRE, Henri. The Production of Space. [1ª ed., 1974]. New York: Blackwell, 1991.

LENCIONI, Sandra. Região e Geografia. São Paulo: Edusp, 1999.

LEOPOLDO, Eudes. A teoria regional na atualização da Geografia Crítica contemporânea: a urbanização da fronteira na Amazônia, a região do Sul e Sudeste do Pará. Confins, n. 44, 2020.

LIMA, Marcos Castro de. A geografia como produção das dimensões política, jurídica e ideológica: imbricação triádica estrutural da Região Metropolitana de Manaus. Confins, n. 43, 2019.

NIETZCHE, Friedrich. Assim falava Zaratustra. Rio de Janeiro: Edições de Ouro, 1966. 
OLIVEIRA NETO, Thiago, NOGUEIRA, Ricardo José Batista. Os transportes e as dinâmicas territoriais no Amazonas. Confins, n. 43, 2019.

OLIVEIRA, José Aldemir de. A produção da cidade na Amazônia: tempos e espaços de ações e reações. In: SPOSITO, Eliseu Saverio; SILVA, Charlei Aparecido da; SANT'ANNA NETO, João Lima; MELAZZO, Everaldo Santos (orgs.). A diversidade da geografia brasileira: escalas e dimensões da análise e da ação. Rio de Janeiro: Consequência, 2016.

SANTOS, Milton. La Naturaleza del Espacio: técnica y tiempo, razón y emoción. [1ª ed., 1996]. Barcelona: Ariel, 2000.

SANTOS, Tiago Veloso dos; SOUSA, Isaque dos Santos; LIMA, Susane Patrícia Melo de. Os grandes objetos urbanos: condição, meio e produto da metropolização regional na Amazônia brasileira. Acta Geográfica, vol. 12, n. 29, 2019.

SARAMAGO, José. Ensaio sobre a cegueira. Rio de Janeiro: Companhia das Letras, 1995.

TRINDADE JÚNIOR, Saint-Clair da. Diferenciação territorial e urbanodiversidade: elementos para pensar uma agenda urbana em nível nacional. Cidades, vol. 7, n. 12, 2010.

VIDAL DE LA BLACHE, Paul. Princípios de Geografia Humana. [1ª ed., 1921]. Lisboa: Cosmos, 1954. VIRILIO, Paul. O espaço crítico: e as perspectivas do tempo real. São Paulo: Editora 34, 1993.

\section{ABSTRACTS}

In the literature review about the Covid-19 spread worldwide, the return to the private space and the possible generational changes are the most stressed. However, little is said directly about the representations field, which ends up in the background due to the whirlwind of systematic tragic facts, which daily bring up the limits of what we conventionally call civilization. The aim is then to think and problematize, in the new critical space-time of the Covid-19 pandemic, processes and representations of the contemporary world and their reproduction in the Amazon and, in particular, in the border region, the South and Southeast of Pará.

No amplo espectro de desdobramentos apontados sobre a disseminação da Covid-19 no mundo, o retorno ao espaço privado e as possíveis mudanças geracionais são as mais frisadas. No entanto, pouco se fala diretamente sobre o domínio das representações, que acaba ficando em segundo plano diante do redemoinho de fatos trágicos sistemáticos, que trazem a tona cotidianamente os limites do que convencionamos chamar de civilização. 0 objetivo é então pensar e problematizar, no novo espaço-tempo crítico da pandemia da Covid-19, processos e representações do mundo contemporâneo e sua reprodução na Amazônia e, em particular, na região de fronteira, o Sul e Sudeste do Pará.

En el amplio espectro de interrogantes planteados sobre la propagación de Covid-19 en el mundo, el retorno al espacio privado y los posibles cambios generacionales son los más destacados. Sin embargo, poco se dice directamente sobre el dominio de las representaciones, que termina en segundo plano debido al torbellino de hechos trágicos sistemáticos, que diariamente traen los límites de lo que convencionalmente llamamos de civilización. El objetivo es entonces pensar y problematizar, en el nuevo espacio-tiempo crítico de la pandemia de Covid-19, los procesos y las representaciones del mundo contemporáneo y su reproducción en la Amazonía y, en particular, en la región de frontera, el Sur y Sureste de Pará.

Dans un large spectre de questions autour de la dissémination mondiale de la covid-19, le retour aux espaces privés et des probables changements générationnels sont les plus soulignés. 
Néanmoins, face au tourbillon de faits tragiques responsables de mettre en cause ce qu'on appelle la civilisation, on ne mentionne pas beaucoup le rôle des représentations. Ainsi, à partir du nouvel espace-temps critique de la pandémie, on veut réfléchir sur les processus et les représentations du monde contemporain et sa reproduction dans l'Amazonie, notamment dans la région frontière, le Sud et le Sud-est du Pará.

\section{INDEX}

Keywords: contemporary world; Amazon; border; representation; Covid-19 pandemic.

Palabras claves: mundo contemporáneo; Amazonas; frontera; representación; pandemia de Covid-19.

Palavras-chave: mundo contemporâneo; Amazônia; fronteira; representação; pandemia da Covid-19.

Mots-clés: monde contemporain; Amazonie; frontière; représentation; Pandémie Covid-19.

\section{AUTHOR}

\section{EUDES LEOPOLDO}

Professor Adjunto da Universidade Federal do Sul e Sudeste do Pará (FCH/IETU/UNIFESSPA). Email: eudesleopoldo@gmail.com 